\section{Making HRM curriculum relevant - a hypothetical practitioners' guide}

Making HRM

curriculum relevant

\author{
Vic Benuyenah
}

School of Business, Economics and Informatics, Birkbeck University of London, London, UK and

Higher Colleges of Technology, Dubai, United Arab Emirates, and

Bistra Boukareva

Department of Business, Higher Colleges of Technology, Dubai, United Arab Emirates
Received 14 September 2017

Revised 1 December 2017 1 May 2018

Accepted 18 May 2018

\begin{abstract}
Purpose - Despite business schools teaching human resources management (HRM) for several decades, the skill set of graduates today fails to match the requirements of the industry. Although some attempt has been made to make the HRM curricula relevant, in most cases, a large gap exists between the subject, its assessment and the industry demands. The purpose of this paper is to illustrate the changing trends in the field of HR and present ideas that will guide modern HRM curriculum development.

Design/methodology/approach - The paper draws on professional experience of the authors in teaching and developing HR curricula as well as literature illustrations from work-based learning.

Findings - To achieve relevancy, HR curricula need to focus more on professional work-based skills that are pertinent to the contemporary workplace and re-structure exam formats to be in line with skills required in the HR profession.

Research limitations/implications - There is an opportunity to test the ideas expressed in this paper empirically; this can normally be done through a triad focus group including employers, students and teachers. Originality/value - The paper is predicated on the mismatch between the teaching and assessment of some HR subjects and the needs of the contemporary HR profession.
\end{abstract}

Keywords Work-based learning, Contemporary HRM curriculum, HRM curriculum, HRM teaching,

Work placement

Paper type Viewpoint

\section{Introduction}

The business world is changing exponentially and so is the practice of human resources management (HRM). Some of the key changes in the business field over the past two decades include the diversity of digital platforms available to educators and students of HRM. In the fast changing business world, methods, tools and processes used in recruitment and selection, training and development are vastly different compared to just three decades ago. It is apparent that business schools will be better off if they can adapt their teaching and course offering to the changing needs of industry. In the field of HR practice, changes have occurred in the recruitment, selection, training and appraisal methods and the processes used in ensuring that these core functions of HR are strategically fit for purpose. Possibly, a long list of changes occurring in the business world exists albeit this is not the focus of this paper. In some sectors, educational transformation has been embraced particularly in the field of

(C) Vic Benuyenah and Bistra Boukareva. Published in the Journal of Work-Applied Management. Published by Emerald Publishing Limited. This article is published under the Creative Commons Attribution (CC BY 4.0) licence. Anyone may reproduce, distribute, translate and create derivative works of this article (for both commercial and non-commercial purposes), subject to full attribution to the original publication and authors. The full terms of this licence may be seen at http://creative commons.org/licences/by/4.0/legalcode 
JWAM

10,1

94

teaching and learning although such a change is mainly in approaches to pedagogy and less so in content. Recently, Helyer (2015) carried out a study that calls for reflective thinking in work-based learning (WBL) emphasising that such an approach promotes adaptable behaviours that can address the changing roles in today and future jobs market. Such a radical move to incorporate hitherto unpopular methods of assessing learning is defensible, and has been supported by others including Garnett and Cavaye (2015) and Morris and Blaney (2014) who advocated for the recognition of prior learning (RPL) practiced widely by Teesside University, University of Lancaster and Middlesex University. Still, there are gaps in the curricula of several other universities. As the gap between subject matters, current HRM practices, teaching practices and assessment methods continue to widen, a number of scholars in HR (Herman, 2007; Martin-Rios et al., 2017) and in other educational work (Garnett et al., 2016; Graham, 2017) have expressed their concern, calling for a review of the approach taken in educating the modern HRM graduate. One area in particular that lags behind in educational practice is the method by which students of HRM are assessed - this is not exclusive to HRM; several higher educational institutions including, high-ranking universities in the UK, Australia as well as several government institutions in Vietnam and most of the developing world, continue to still assess their students in the traditional way-typically, a 3-h final exam aimed sometimes, and unintentionally, at regurgitation of semestral course material that features theories often formulated five decades ago. A quick scan through the website and academic calendars of these universities will reveal evidence of scheduled examinations for courses that are not necessarily theoretical in nature, for example, a formal exam for a course in recruitment and selection or training and development raises questions about what skills are being measured through these formal exam-based summative assessments. This practice in itself has some academic merits; however, in contrast, Harvard Faculty of Arts and Sciences adopted a motion in support of eradicating final exams except in cases where the faculty makes a request to the registrar to end a course with a formal, seated exam.

Another area of $\mathrm{HR}$ teaching that requires recalibration is the integration of industry learning which partially falls under the two major categories of WBL and RPL that were previously mentioned in this paper. Whilst we aim to spark a debate that discusses some of the above issues, our proposal is not to discard the current HRM curricula as we equally love HRM theories and models and would like students to be conversant with such information, but at the same time, we would like to see an HRM educational system that leans a lot more towards a very practical and professional curricula. This way the HRM student will be prepared and work-ready when they join the labour force wherever they find themselves. Like any other discipline in the business field, research has supported the view that changes are necessary (Clark, 1994; McGraw, 2004; Zhu and Warner, 2004). Zhu and Warner (2004), for example, spelled out the shift in HR practice after China's accession to the WTO whilst Rahman et al. (2018) argued for promulgation of e-HRM practices to be in line with the changing trends in the information technology sector. Building on these views and our own experience teaching and developing HR courses, we identify the following key influences that define the current HRM field:

- rate of internet adoption can transform HR practice;

- a relativist HRM approach exists out there in the world;

- no two organisations are the same in terms of how they operate;

- students need to experience diverse HRM situation before graduating;

- most organisations today prefer a "ready-made" graduate;

- the HRM role is ever expanding and varying based on the context;

- more industry-university partnership better prepares graduates; and

- professional bodies are integral part of graduate development programmes. 
These factors are not exhaustive but in our experience of teaching and practicing HRM, we believe that a good first step of HR curriculum development can begin if the above points are considered as a key part of HR teaching (see Figure 3).

Although we have recently seen some changes in traditional methods of instruction featuring a more industry-relevant approach in some renown universities, for example, the Harvard Extension Programme, Oxford's Department for Continuing Education and Cambridge Institute of Continuing Education in addition to the institutions in Australia and the UK that apply the WBL and RPL methods, there are still several undergraduate institutions that continue to follow the traditional "brick and mortar" or "chalk and talk" method in HRM programme offerings.

In support of our view for a changed curriculum is some limited but compelling evidence indicating that higher education curriculum has benefited from changes aimed at meeting the trends in hospitality practice, for example, Martin-Rios et al. (2017). Other scholars have argued for changes in the accounting curricula (Awayiga et al., 2010) to reflect the professional demands of the field of accounting; however, little evidence has been found to support such advocacy in the field of HRM.

With the rate of internet penetration trebling per every decade, any HRM educator or practitioner can see the gap that exists between how HRM is taught in business schools and what the professional practice requires. The assertion from industry experts and student feedback point to the fact that we are not alone in thinking that the teaching practices are slightly anachronistic and too far behind what the industry requires for the contemporary business world. Accordingly, this paper's agenda is not to radically revolutionise the teaching of HRM across the academic institutions out there in the world but we are hoping to start a debate in the area of pedagogy, content and industry-relevance that will hopefully create an opportunity to improve HRM syllabi for the coming years. The guide provided in Figure 3 focusses mainly on the teaching of HRM at the undergraduate level although most of the analysis and recommendations are applicable to other levels of teaching and training.

\section{Traditional HRM practices}

The practice of HRM dates back to several decades although its shape and systems have been largely determined by industrial activities in Europe and North America. A major influence of current HRM practice is the concern for industrial welfare systems, whilst some argue that changes in economic and social systems influence the practice of HRM. Traditionally, the practice of HRM was either carried out by a small team, the business owner (often informally) or by a designated individual who did not really have a background in personnel management or a person who carried out essential administrative functions in the organisation. In the 1920s the practice assumed its maiden name-Personnel Management; this name would become a huge area of academic contention and one that did not really fit the political correctness of our society today.

The generalisability of much published research on when exactly HRM became a separate field of study is problematic, although it is popularly accepted that the scientific management framework began to give way to the human relations school of thought circa 1950. Following the initial attempt to create a separate field of study and practice for HRM, came the revolution in the 1960 s that antagonised the scientific paradigm of people management practices that hired the best, provided extensive training, offered the best possible pay (Mullins and Christy, 2016) but did not really seek to focus on the human behavioural element of organisations. When the scientific paradigm eventually gave way to the soft approach that values personality differences (Cattell, 1966; Allport, 1924), cultural differences (Hofstede, 1980; Hall, 1976; Trompenaars, 1993; Trompenaars and Woolliams, 2003) the teaching of HRM responded accordingly with emphasis on personality and cultural theories. This movement was championed by the school of thought defined as 
JWAM

10,1

Figure 1.

Percentage of

world population

using internet

(December 1995-2017) the "humanist", essentially emphasising the diverse needs of the employees that are found in most international organisations today. In the coming decades, we can envisage a mixture of factors including artificial intelligence, social media trends, immigration dynamics and lithe corporate strategies to determine what the industry and business schools can achieve together.

\section{Contemporary HRM framework}

We define the contemporary HRM era as the period post 2007 as this is the period most parts of the world have experienced a major shift in both technological development and what the CIPD (2017) identified as "the changing context of work". As can be seen from Figure 1, over 3.7bn people are active internet users. This number likely includes young HR professionals currently in higher education and who belong to the "click to find" generation compared to the earlier generation of HRM students. For example, rather than spending hours creating her own curriculum vitae or resume, a student is more likely to adapt an existing template of a CV and modify it to suit her needs-similar ready-made templates are available in Microsoft Word. In the United Arab Emirates, for example, there are more mobile phones than the entire population which is currently over $9.2 \mathrm{~m}$ people (World Bank, 2017). Despite these major shifts in lifestyle particularly access to IT and freely available information, we find that several business schools carry on teaching and assessing HRM graduates with identical tools and subject content that have been used since the 1960s - this leads to a global deficit in relevant IT skills, mental preparedness and soft skills required to fulfil tasks effectively within the HRM setting. A number of business institutions are leading the way in introducing digital and innovative systems to their teaching and learning practices, particularly, in countries where digital revolution is becoming a government priority (UAE, Canada, South Korea, Finland and Singapore). Still, there is a lag in this area of transformation in several institutions across the world.

To see why business schools need to do more to adapt their syllabus to the needs of modern day HRM students, we present the global trend of internet usage from 1995 to 2017 (see Figure 1). There is a huge jump in the overall internet usage from 2005 till date depicting a percentage growth outstripping both population growth (currently averaging around 1 per cent except in Africa) and the increase in the number of new business schools (no data).

Whereas the Telecommunications Regulatory Authority in the UAE reports an increase in the mobile phone usage of 228.3 per every 100 people, there is even a more compelling evidence showing a huge mobile phone penetration all over the world. Our search reveals that there is a 99 per cent mobile broadband penetration in all OECD countries as of July 2017 (OECD, 2017) Previously, the OECD has suggested back in 2003 that the compound annual growth rate of mobile phone usage is in excess of one mobile phone per each person

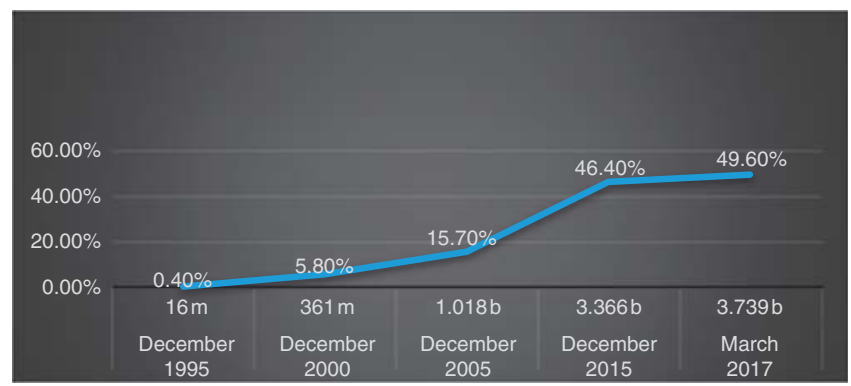

Source: Statista (2017) 
in the population. In recent times, most activities relating to work communication are carried out on mobile phones instead of computers. In 2006, a selected number of countries have reported a massive growth demonstrated by broadband penetration per every 100 inhabitants (see Figure 2).

\section{The proposed HRM teaching guide}

We propose a simple but a logical approach to teaching HRM in the higher education setting. The guide can be effective in teaching full time undergraduate areas of HRM such as recruitment and selection, training and development, and performance management; however, we recognise that this guide may not be applicable to all aspects of HRM teaching, for example, ethics of HRM, since this is more a philosophical enquiry rather than an HRM practice.

We think that a number of variables define the modern HRM framework:

- digital speed and rate of internet penetration;

- higher cultural mix among employees;

- remoteness or proximity of potential applicants;

- modernity of recruitment and selection tools;

- intensity of competition among applicants;

- entrepreneurial mindset;

- inter-disciplinary awareness;

- information logjam;

- legislation;

- proliferation of private enterprises; and

- professional HR bodies across the world.

Based on above variables, we develop a hypothetical guide that will help educators of HRM to make more meaningful contribution to the field of HRM practice.

The guide has eight interactive elements altogether and would serve as a useful guide in developing a modern HRM curriculum. The four outer boxes individually present human, technological, legislative and market forces that determine a typical modern HRM practice and therefore should feature in the design of modern HRM syllabus. These elements are already in

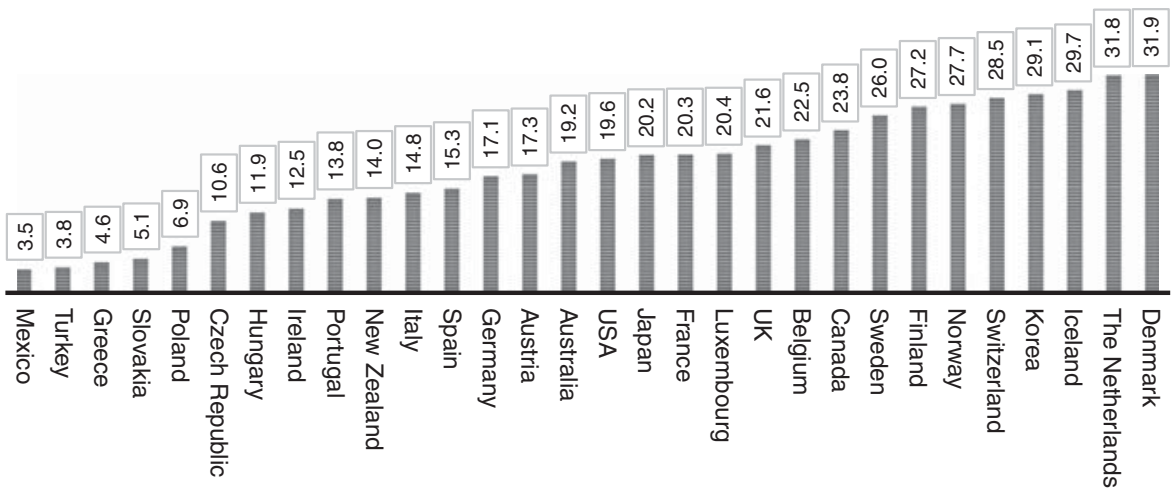

Source: OECD (2017)

Making HRM

curriculum relevant 
JWAM

10,1

existence one way or the other; however, we have provided a detailed list of the sub-elements that need to be considered in the development and teaching of the "new HRM" subject. As the teaching and the practice of $\mathrm{HR}$ are influenced by professional bodies particularly in the UK, Australia, the USA and Canada, any curriculum development initiative at an undergraduate level should essentially include a flavour of current professional requirements. This interaction is represented by the four professional bodies (not exhaustive): CIPD, SHRM, CHRP and AHRI in the model in Figure 3. In the UK and Australia, for example, a professional qualification is mandatory or in some cases preferred for several HR roles. At the individual student level, an inner concentric model encapsulates the co-curricular activities and training programmes that the student should benefit from whilst studying their degree. These include an intensive mentorship programme championed by an HRM expert either within or outside the academic institution, programme advisory conducted continuously to guide the choice of subjects within the programme, individual student strategy to include study plans and an e-portfolio of aims and objectives and how to achieve them, and also internship programmes that are driven by a sound partnership between student-industry-parents-university. Together, the inner and the outer components provide a comprehensive guide that academics can ruminate over while engaged in a revamping exercise for their syllabi.

\section{Recommendation to higher education}

To start the process of revolutionising the HR curricula and making it more relevant will take a huge effort and commitment on the part of academics, programme administrators and even students; however, the successful stories of Australian and UK Universities that already implement, reflective learning, WBL and RPL (Critten, 2016; Helyer, 2015; Morris and Blaney, 2014) approaches to ensure their course offerings are relevant to the changing world can provide an effective example to institutions wanting to emulate such practices. We recommend that curriculum developers take into account the following:

- incorporate quality company visits or guest lectures per semester;

- cross-cultural relevance and appeal of the subject matter;

Figure 3.

Contemporary HRM Curriculum Model

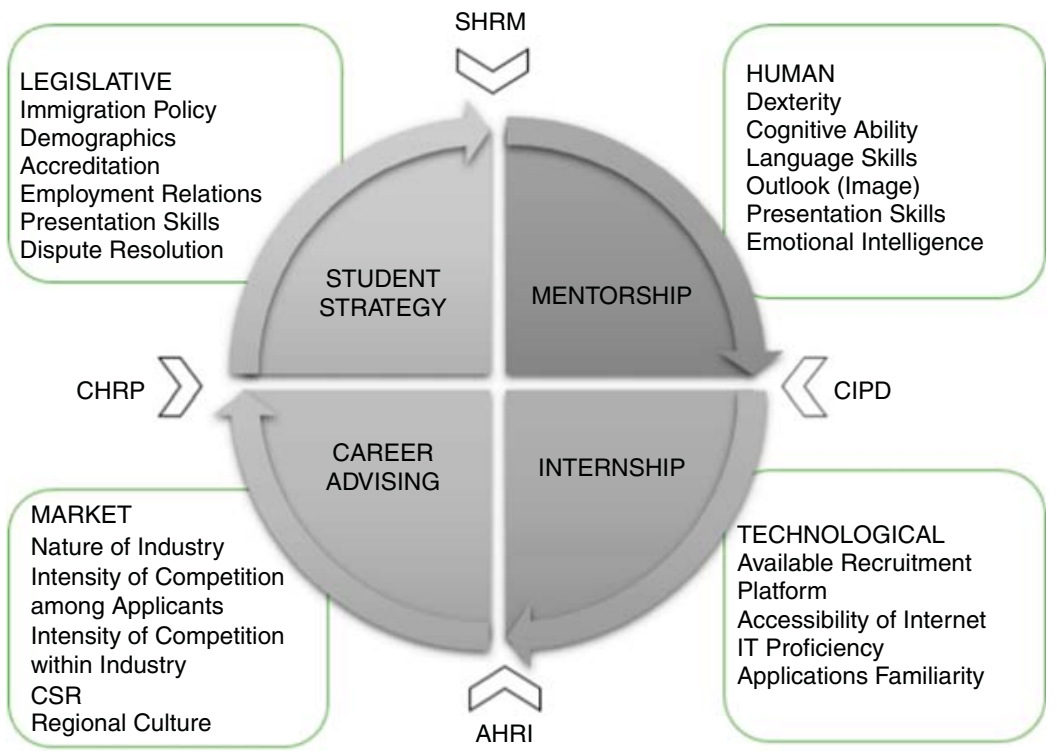


- introduction of business analytics as part of the curriculum;

- a framework to teach appropriate dress code (currently taken for granted);

- recruitment and selection preferences of applicants (CV vs LinkedIn);

- reduced attention span of modern learners;

- proliferation of free and easily accessible subject materials online;

- personality and characteristics of contemporary employees;

- balance between social and corporate life (work is no longer a 9 to 5 job in some cases);

- a "brick and mortar" vs online syllabus; and

- changing context of socio-political environment.

\section{Conclusion}

Our objective in this opinion piece was to spark a debate that will eventually lead to revolutionising the HRM curriculum and teaching in higher education settings. We have provided arguments against the status quo whilst outlining our observation of the widening gap between technological improvements and the teaching of HRM as well as the gap between the contextual nature of modern HRM practice and the lags in pedagogical reformations within the HRM curricula. It is observed that although different sets of data point to a universal technological advancements particularly in internet and mobile penetration, the teaching of HRM has not fully responded to accommodate these changes.

We believe the Contemporary HRM Curriculum Guide discussed above will serve as a useful instrument that will provide a revolutionary framework for institutions, academics and practitioners working on a new HRM syllabus. Despite this attempt, we acknowledge that this model lacks empirical evidence and therefore will require a further research to validate the views presented in this paper.

\section{References}

Allport, G.W. (1924), "The study of the undivided personality”, Journal of Abnormal Psychology and Social Psychology, Vol. 19, pp. 132-141.

Awayiga, J.Y., Onumah, J.M. and Tsamenyi, M. (2010), "Knowledge and skills development of accounting graduates: the perceptions of graduates and employers in Ghana", Accounting Education: An International Journal, Vol. 19 Nos 1-2, pp. 139-158.

Cattell, R.B. (1966), "The screen test for the number of factors", Multivariate Behavioral Research, Vol. 1, pp. 245-276.

CIPD (2017), Chartered Institute of Personnel and Development, available at: www.cipd.co.uk/newsviews/news-articles/annual-conference-ireland\# (accessed 28 June 2017).

Clark, I. (1994), "HRM - the reinvention of modern management?", Personnel Review, Vol. 23 No. 5, pp. 15-24, available at: http://doi.org/10.1108/00483489410067781

Critten, P. (2016), "A radical agenda for enabling organisation transformation through work-applied learning", Journal of Work-Applied Management, Vol. 8 No. 1, pp. 65-78, available at: http://doi. org/10.1108/JWAM-05-2016-0006

Garnett, J. and Cavaye, A. (2015), "Recognition of prior learning: opportunities and challenges for higher education", Journal of Work-Applied Management, Vol. 7 No. 1, pp. 28-37, available at: http://doi.org/10.1108/JWAM-10-2015-001

Garnett, J., Abraham, S. and Abraham, P. (2016), "Using work-based and work-applied learning to enhance the intellectual capital of organisations", Journal of Work-Applied Management, Vol. 8 No. 1, pp. 56-64, available at: http://doi.org/10.1108/JWAM-08-2016-0013 
JWAM 10,1
Graham, D. (2017), "Embedding employability behaviours", Journal of Work-Applied Management, Vol. 9 No. 1, pp. 35-50, available at: http://doi.org/10.1108/JWAM-01-2017-0001

Hall, E. (1976), Beyond Culture, Anchor Books, New York, NY.

Helyer, R. (2015), "Learning through reflection: the critical role of reflection in work-based learning (WBL)", Journal of Work-Applied Management, Vol. 7 No. 1, pp. 15-27.

Herman, S.J. (2007), "Teaching contemporary human resource management”, Journal of Management Education, Vol. 32 No. 4, pp. 143-145.

Hofstede, G. (1980), Culture's Consequences: International Differences in Work-Related Values, Sage Publications, Beverly Hills, CA.

McGraw, P. (2004), "Influences on HRM practices in MNCs: a qualitative study in the Australian context", International Journal of Manpower, Vol. 25 No. 6, pp. 535-546, available at: http://doi. org/10.1108/01437720410560433

Martin-Rios, C., Pougnet, S. and Nogareda, A.M. (2017), "Teaching HRM in contemporary hospitality management: a case study drawing on HR analytics and big data analysis", Journal of Teaching in Travel \& Tourism, Vol. 17 No. 1, pp. 34-54.

Morris, C. and Blaney, D. (2014), "Work-based learning”, Understanding Medical Education: Evidence, Theory and Practice, pp. 97-109, available at: http://doi.org/10.1108/JWAM-04-2017-0008

Mullins, L. and Christy, G. (2016), Management and Organisational Behaviour, 11th ed., Pearson, Harlow and New York, NY.

OECD (2017), "Broadband statistics", available at: www.oecd.org/sti/broadband/oecdbroadbandstatistic stodecember2006.htm (accessed 1 December 2017).

Rahman, M., Mordi, C. and Nwagbara, U. (2018), "Factors influencing E-HRM implementation in government organisations", Journal of Enterprise Information Management, Vol. 31 No. 2, pp. 247-275, available at: http://doi.org/10.1108/JEIM-05-2017-0066

Statista (2017), "World internet user penetration", The Statistics Portal, available at: www.statista.com/ statistics/325706/global-internet-user-penetration/ (accessed 30 November 2017).

Trompenaars, F. and Woolliams, P. (2003), Business Across Cultures, Capstone Publishing, Chichester.

World Bank (2017), "Mobile cellular subscriptions", available at: https://data.worldbank.org/indicator/ IT.CEL.SETS.P2 (accessed 21 November 2017).

Zhu, Y. and Warner, M. (2004), "Changing patterns of human resource management in contemporary China: WTO accession and enterprise responses", Industrial Relations Journal, Vol. 35 No. 4, pp. 311-328, available at: http://doi.org/10.1111/j.1468-2338.2004.00316.x

\section{Further reading}

Kavanagh, M. and Drennan, L. (2007), "Graduate attributes and skills: are we as accounting academics delivering the goods?", paper presented to Accounting \& Finance Association of Australia and New Zealand Conference, Gold Coast.

Telecommunications Regulatory Authority (2017), "UAE's mobile phone penetration", available at: www.tra.gov.ae/en/media-hub/press-releases/2016/10/23/tra-reveals-data-for-second-quarterof-2016-on-uae-market-shares-of-mobile-handsets-smartphones-and-social-networking-sites. aspx (accessed 12 September 2017).

Trompenaars, F. and Hampden-Turner, C. (1997), Riding the Waves of Culture: Understanding Cultural Diversity in Business, 2nd ed., Nicholas Brealey Publishing, London.

\section{Corresponding author}

Vic Benuyenah can be contacted at: vbenuy01@mail.bbk.ac.uk

For instructions on how to order reprints of this article, please visit our website:

www.emeraldgrouppublishing.com/licensing/reprints.htm

Or contact us for further details: permissions@emeraldinsight.com 